DOI: 10.21608/zviz.2019.28661.

\title{
Studies of Reproductive Changes during Pregnancy in the Bitch
}

\author{
Faten M. Labib, El Azab A. El Azab, Hassan H. Mansour, Atef B. Mahdy and Asmaa A. \\ Abdallah* $^{*}$
}

Theriogenology Department, Faculty of Veterinary Medicine, Zagaig University, 44511, Egypt

\begin{abstract}
In the present study, seven mongrel bitches were used, their age ranged from 15 months to 3 years. Vaginal cytology was carried out during pregnancy period of these bitches by taking vaginal smears weekly to investigate vaginal cytological changes. Serial ultrasonography was performed daily on these bitches from the $15^{\text {th }}$ day after the last breeding until birth day to determine the time of appearance of different gestational structures. The first observation of the extra-fetal and fetal structures was as follows: The yolk sac membrane was first detected as an echogenic U-shaped fetal membrane in a range of 24-25 days. A third echogenic fetal membrane, allantoic membrane, was first detected on Day 27. On Day 23, in the uterine wall surrounding the gestational sac, an apparently hyperechoic inner layer was differentiated to the zonary placenta which appeared as two thick bands one on either side of the fetus on Day 29. The embryo appearance was on Day 20.5. The early time of the position of the embryo either opposed to the uterine wall or dependent on chorionic cavity was nearly on Day 22 and on Day 24 , respectively. The heartbeat, which is one of fetal vital signs, was detected as a bright echogenic flickering motion on Day 21. On Day 26 in mongrel bitches, the features of the embryo changed from an oblong to bipolar shape and form two loops of number 8 , size and density the same. An anechoic area in the head of the embryo was detected on Day 29. The limb buds were firstly detected on Day 29. Fetal movement was firstly detected on Day 33. Meanwhile, the skeleton of the fetus was first detected as hyperechoic structure on Day 33.
\end{abstract}

Keywords: Reproduction, Pregnancy, Bitch, Ultrasonography

\section{Introduction}

Dogs have become an important household pet in Egypt. They had a valuable role in the community, police and army forces, rescue organizations, services and assistance work. Also, they are used in herding, gardening, cadaver detection, war dog, racing, sledding, rat extermination and hunting. In recent years, there was a great interest with management and care of dogs in Egypt. Dogs were introduced to the veterinary hospital for pregnancy diagnosis, following up pregnancy, dystocia cases, vaccination of dogs and general illness. The average gestation length in the bitch is normally quoted as 63-64 days, but the interval from first mating to whelping can vary from 65 to 71 days. There were a several methods for pregnancy diagnosis and following up pregnancy in the bitch as: physical changes, vaginal cytology, abdominal palpation, radiography and sonography. Physical changes were not accurate for pregnancy diagnosis due to such clinical changes occurs in pseudo pregnancy in the bitch. Abdominal palpation was easy and safe method but, not accurate, diagnosis pregnancy late at $25^{\text {th }}$ day post insemination and difficult to palpate after $35^{\text {th }}$ day. Radiography was useful for estimating numbers of feti during pregnancy but, used too late after 42 days post insemination.

Vaginal cytology is the most useful clinical laboratory tool for management breeding in the bitch, monitoring the oestrous cycle and pregnancy diagnosis but not used for prediction of parturition date. Ultrasonography has rapidly become established as one of the principal imaging techniques used in veterinary practice. It is an excellent way, very sensitive, specific imaging method to diagnose pregnancy early on Day 19 after breeding in the bitch and used for prediction of the parturition date. It is an accurate, safe for animal, puppies and operator and gives more information on the developmental stages of the fetus. By sonography, Viability of the puppies can also be determined by detection of heart beats.

The puerperium is the period in which the genital system prepares to return to cyclicity 
and involuted to prepartum state. By sonography, the operator can differentiate between normal and abnormal postpartum uterus and follow up the involution of both the uterus and the ovaries as shown Feldman and nelson [1].

Therefore, the present study is planned to achieve the following points: Investigate the vaginal cytological changes at different stages of pregnancy. Diagnosis pregnancy at the first time and try to estimate the gestational age by establishing the time of the first observation of the extra-fetal structures and the fetal structures by sonography. Record the rate of feti resorption in pregnant bitches if present.

\section{Material and Methods}

\section{Animals}

Seven mongrel bitches of different weights ranged from 9 to $11 \mathrm{~kg}$, and their age ranged from 15 months to 3 years. They were housed in the clinic of veterinary hospital in faculty of veterinary medicine, zagazig university, Egypt and reared during the duration of the research.

\section{Vaginal cytology}

Vaginal cytology was carried out along pregnancy period of each bitch by taking vaginal smear weekly after refusal the bitch to be mated from the male to investigate vaginal cytological changes during pregnancy. It was applied on 7 bitches.

\section{Ultrasonography}

In the present work, ultrasound (Esaote Mylab, Germany) was used for reproductive examination in bitches. Ultrasonographic examinations were performed daily from Day 15 after last breeding to parturition day. All animals were examined using real-time Bmode ultrasonography in dorsal recumbancy. The linear probe ( 8 or $10 \mathrm{MHZ}$ ) was used for ultrasonography. Before examination, abdominal skin was shaved and the bitch was positioned in dorsal or lateral recumbancy. Uterus was longitudinally visualized. Urinary bladder was chosen as a reference organ throughout the examination, the uterine horns were measured transversally and the data was recorded Measurements $(\mathrm{cm})$ were taken from two conceptions at least in the same bitch] using the formula of fetal age and prediction of parturition date estimation in Beagle bitches of
Yeager et al [2] as follows : For pregnancy < 40 days, Gestational Age (GA) is: $\mathrm{G}=(6 \mathrm{x}$ GSD or ICCD) + 20, where GSD is Gestational sac diameter and ICCD is Inner chorionic cavity diameter. For pregnancy $>40$ days (GA) is: $\mathrm{GA}=(15 \times \mathrm{BPD}$ or $\mathrm{HD})+20$, where HD is Head diameter and BPD is Biparietal diameter. Days before Parturition $(\mathrm{DBP})=65-\mathrm{GA}$. ICCD or GSD was measured at the location of zonary placenta once it was detectable from Day 20 to Day 39 of pregnancy. It was calculated to be the mean value of the dorsal to the ventral and medial to lateral diameters. HD was measured as the largest cross-sectional diameter of the head or the biparietal diameter when this structure was well identified in longitudinal section from Day 40 to parturition day. Such measurements were taken twice from two feti at least from the same mother. Feti resorption and their rate were recorded by sonography during pregnancy period in the bitches if present. During pueperium, following up postpartum uterine involution by sonography by recording the sizes of uterus at puerperium until complete involution. At this period, this study was performed on only 6 bitches (2 primiparus, 4pleuriparus) due to $7^{\text {th }}$ mongrel bitch was aborted at Day 45 of pregnancy and other bitches whelped normally. The first bitch delivered nine puppies, the second and third bitches had six ones/each, the fourth bitch whelped four puppies, the fifth and the sixth bitches gave birth one and three puppies, respectively. All bitches had good overall clinical status and body temperature was in normal limits. Ultrasonography of the uterus was carried out on the day of whelping (D0) and at each of the following days D1, D7, D14, D21, D28, D35, D42, D49, D56, and D63.

\section{Statistical analysis}

Statistical analysis was performed using the Statistical Package for Social Sciences version 21.0 (SPSS for Windows 21.0, Inc., Chicago, IL, USA).

\section{Results}

\section{Vaginal cytology during pregnancy period}

On the first week of pregnancy, there is a sharp decrease of superficial cornified cell, the decrease reaches to $80 \%$ at the first two days 
of diestrus period and SCC appeared by low percent as $10 \%$ at the end of the first week. Sudden appearance of small intermediate cell and parabasal cell. Neutrofil return in appearance by low percent after completely disappearance in estrus phase. Complete absence of SCC and appearance of large intermediate cell by low percent as $10 \%$ were shown during the second week of pregnancy. On the third week of pregnancy, the SIC were present at 50\%, PBC remained at 30\%, NEU were present at $10 \%$ and LIC were present at $10 \%$ in the vaginal smear. During the fourth and the fifth week of pregnancy, both the SIC and PBC reach to $45 \%$, while the LIC remained at $10 \%$ with complete absence of NEU in the vaginal smear. On the sixth week of pregnancy, the SIC, PBC and LIC were resent at $50 \%, 40 \%$ and $10 \%$, respectively in the vaginal smear. During the seventh and the eighth week of pregnancy, the SIC reached to their peak at $70 \%, \mathrm{PBC}$ were present at $15 \%$ and LIC appeared at $15 \%$ in the vaginal smear.

\section{Ultrasonographic examination}

\section{The time of initial detection of extra-fetal structures}

The anechoic spherical gestational sac compared with the hyperechogenic uterus was firstly detected on Day 17. The first appearance of the yolk sac was recorded as an echogenic U-shaped fetal membrane in a range of 24-25 days. Moreover, the yolk sac appeared as tubular shape in a range of 26-27 days. The yolk sac was first detected as folded cross section one day earlier in the mongrel breed. The third echogenic fetal membrane, (allantoic membrane) was firstly identified on Day 27. On Day 23 zonary placenta appeared as two thick bands one on either side of the fetal sac, between the fetal sac and the uterine wall when imaged in the longitudinal plane and wraps around the central portion of the conceptus like a waistband on Day 29.

\section{The time of the early appearance of embryo \& development}

Concerning findings of ultrasonographic examination to detect the early appearance of the embryo and its development, the embryo appearance was on Day 20. The early time of the position of the embryo either opposed to the uterine wall or dependent on chorionic cavity was nearly on Day 22. The fetal vital sings as the heart beat appear as a bright echogenic flickering motion on Day 21. On Day 26 the shape of the embryo turned from an oblong to bipolar shape and forms two loops of number 8 shape with the same size and density. An anechoic area in the head of the embryo was detected on Day 29. The first observation of fetal buds was on Day 29.

\section{The time of the first observation of fetal organs}

The first observation of fetal movement was on Day 33. Meanwhile, the skeleton of the fetus was first detected as hyperechogenic structure on Day 33. Concerning the fetal abdominal viscera that were firstly detected, the stomach and the urinary bladder were firstly detected on Day 34 and on Day 36, respectively. On Day 37, the lung was detected as hyperchogenic structure. Later on by 3-4 days, the liver was observed as hypoechoic organ compared with the rest of the abdominal organs. 

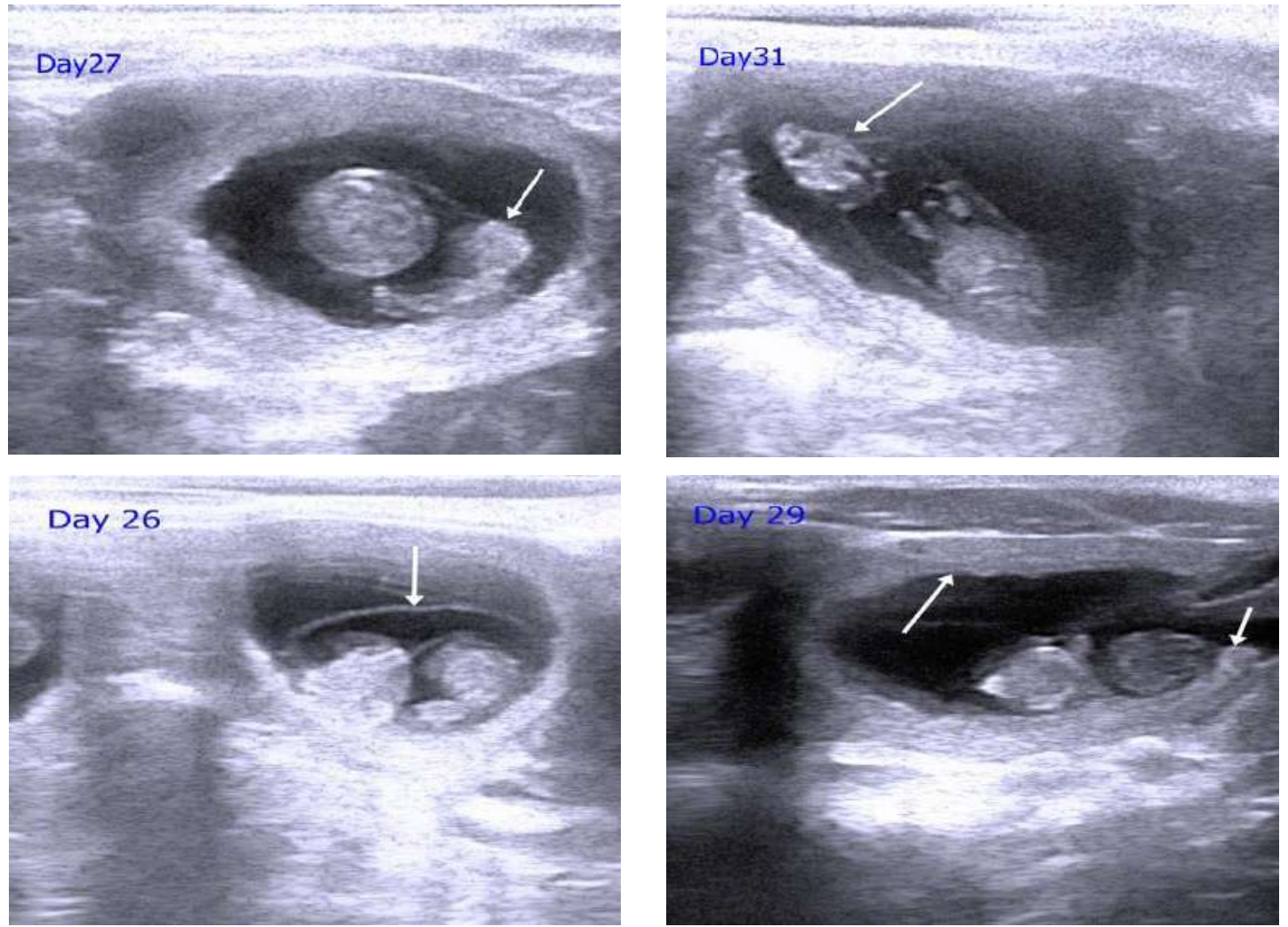

Figure 1: Ultrasonographic appearance of the extra-fetal structures in pregnant bitch, Day 26: white arrow directed on allantoic membrane, which appear an echogenic fetal membrane. Day 27: longitudinal image of gestational sac contained embryo and the tubular shape of the yolk sac (white arrow).Day 29: longitudinal image of gestational sac, (white arrow) show zonary placenta which appeared as two thick bands, one on either side of the fetal sac and cylindrical in shape and folded inward at the edges. Day 31: longitudinal image of gestational sac contained embryo and folded cross section of yolk sac (white arrow).

\section{Estimation age of pregnancy and prediction of birth date}

By using a formula of Yeager et al [2] on the Beagle pregnant bitches, the first day of pregnancy is the day of the breeding, so the GA after LH surge equal to the GA after the breeding plus four days. The GA from day 20 to day 38 depended on dimensions of GSD while, from day 40 to day 58 depended on dimensions of HD, and DBP $=60-$ GA. The length of the gestation period from the last day of breeding was $60 \pm 1.40$.

\section{Feti resorption and fetal death during gestational period}

In the present study, out of seven mongrel bitches, only one mongrel bitch had embryonic death on Day 30 of pregnancy after the last breeding. In this bitch, death occurs in two out of eight embryos and followed by complete resorption of these embryos without vaginal discharge. The sonographic aspects of a resorption were an absence of the embryonic heartbeat, distortion of gestational sac, a reduction in the size of the embryo; an increase in echogenicity of the embryonic fluids. The uterus remained enlarged in this region containing a small volume of free luminal fluid and the uterine wall appeared moderately hyperechogenic. In the same bitch, on Day 45 of pregnancy after the last breeding, death of the other six fetuses was happened and discovered by similar previous findings and followed by abortion on days 26 to 31 of pregnancy.

\section{Follow up uterine involution during puerperium}

On D0 (day of parturition), the uterine diameter at the placental site was $5.33 \pm 0.33$ and it was observed that central luminal fluid 
was not invariably anechoic and had echogenic regions within it. On D1 (first day of puerperium), the uterine diameter at the placental site was $4.41 \pm 0.31$ and observed that the echogenic regions decrease in size, but still presented. On D7, the uterine diameter was $2.50 \pm 0.25$ and it was obviously seen that the echogenicity of the uterus was more homogenous. On D14, the uterine diameter was $2.35 \pm 0.29$ and it was seen that uterus decrease in size and still echogenically homogenous.

On D21, the uterine diameter at the placental site was $1.71 \pm 0.21$. The uterine diameter at the placental site was continued to decrease until reached to $1.44 \pm 0.26$ on D28. On D35, mean and SD of uterine diameter was $0.82 \pm 0.14$. The ultrasonographic examination of the uterine diameter on D56, D63 and after that, revealed difficulty and impossible to monitor uterus due to intestinal gas, however, it was clearly determined that the uterine diameter at the placental site decreased.

\section{Discussion}

Vaginal cytology is the most laboratory tool for management breeding in the bitch, monitoring the estrous cycle and pregnancy diagnosis. In the present study, vaginal cytology during pregnancy period characterized by sharp decrease in SCC and presence of SIC, PBC and NEU. This was established in previous studies of Johnston et al [3]. Ultrasound imaging has a major role in the documentation of the normal physiological events as well as the diagnosis and staging of pregnancy. Ultrasonographic observation throughout pregnancy can be used to estimate age of pregnancy, level of fetal growth and the birth date. In the current study, the early diagnosis of pregnancy by ultrasonographic examination in bitches can be made usually ranges from days [16-19] after breeding when an anechoic gestational sac surrounded by uterine wall was observed. The current results are in agreement with those of Yeager et all. and Yeager\& Concannon [2, 5], who stated that the gestational sac was firstly observed at 17-19 days after ovulation and on Day 20 after LH surge, respectively, but these results were controversial with those obtained by other rearchers as Bang \& chang and Aissi $[4,6]$, who reported that the gestational sac was firstly detected on 17-21days after LH surge and on days 16-21 after the first copulation, respectively. The differences in these results for early detection of pregnancy might be due to using another frequency for transducer and using different breeds, so these conditions might affect the time of observation. In particular, the early observation of pregnancy in this study (as early as Day 16 of gestation) was achieved using a higher frequency probe (10 MHZ) due to this higher frequency can be detected small structures which measured by millimeter.

Hyperechogenic inner layer which present in the uterine wall and surrounding the gestational sac was differentiated to the zonary placenta on Day 23, this result was confirmed by results obtained by Yeager et al. [2] and Aissi et al. [7] and contrasted with the findings of Yeager and Concannon [5] who firstly detected hyperechogenic inner layer of uterine wall which differentiated to the zonary placenta on days 23-26 after ovulation. This difference might be caused by differences in breed. The first appearance of the embryo and the flickering motion of the heart beat were firstly detected on Days 20-22 and on Days $22-23$, respectively. These results were on the same line of the results obtained by Yeager $e t$ all. and Bang\& Chang [2,4] who firstly detected the embryo heart beat on days 23-25 after LH surge and agreed with the results obtained by Aissi [6] and Aissi et al. [7]. Comparing the results of the time of. appearance of the different anatomical characteristics and those obtained previously by Yeager et al. [2] and Aissi [6] in pregnant Beagle bitches in days after LH surge. Most fetal organs were detected between days 30 to 50. At this time the fetal organs were first observed as skeleton, stomach, urinary bladder, kidney and hypoechoic liver in the present study and other studies as evidenced formerly by many authors as Yeager et al, Yeager et al. [2], Yeager and Concannon [5] and Aissi et al. [7]. Ultrasonography is a useful imaging modality for the estimation of gestational age and the prediction of parturition day. In our study prediction of birth day by recording the initial detection of extrafetal structures and fetal structures by sonography was done. Taking measurements 
of gestational structures using ultrasonography then applying equation used by Yeager et all. [2]. The results of this study revealed that the regressions of GSD were significantly related to the GA and GSD increased with progression of GA. These results agreed with the preceding work findings of Yeager et al. [2] and Son et al. [8]. Of the extra-fetal structures as outer uterine diameter, GSD and the length of the zonary placenta, GSD were easier to measures than the other extra-fetal structures because they were seen distinctly as anechoic round structure with overt bounds that produced characteristic bright specular echoes and it showed the best correlation of the gestational age before Day 38. After Day 38, the uterus was converted into irregular shape in the cross-section and grew slowly. The relative volume of fetal fluids decreased compared with the size of fetus and the fetus was closely associated with the wall of chorionic cavity. For these reasons, above structures were difficult to be measured after Day 38, therefore, GSD on Days 20 - 38 was the most suitable to estimate the GA and predict the parturition day. Out of fetal structures, HD increased at fixed rate and the regression was significantly and linearly related to the gestational age on Day 40 to parturition and HD increased with progression of gestational age. Such results coincided with earlier results of Yeager et al. [2] and Son et al. [8]. After Day 28 when fetal head could be identified, Fetal HD was possible to measure, but the reliable measurement of fetal $\mathrm{HD}$ on days 28 to 37 was disturbed because ossification of the skeleton was defective and allantoic membrane was closely associated with fetus. In the present study, for prediction of parturition date, with the exception of 1 mongrel bitch (8\%) having 1 fetus, 9 out of 13 bitches $(69.2 \%)$ delivered exactly on the date predicted and 3 out of 13 bitches (23\%) delivered within 1 day more than the date predicted. These results agreed with the results reported by Yeager et al. [2]. By way of exception, 1 mongrel bitch had only one fetus, the actual parturition day was 3 days later than the predicted parturition day made on basis of measurements of GSD and HD, due to the larger size of a singleton litter, this result was on the same line of previous studies of Son et al. [8] and Anna et al. [9]. In the current study, out of 13 bitches only one mongrel bitch (Bitch No: 7) had embryonic death on Day 30 of gestation after the last breeding. It is easier for following the uterine horns beyond the cranial margin of the bladder by sonography due to enlargement of the post partum uterus in diameter than normal non pregnant uterus. In the current study, it was seen that the uterine horns remained enlarged and fluid filled for a variable time after parturition. The post-partum uterine involution may be easily interpreted by ultrasonography in bitches; therefore, uterine enlargement disappears approximately till the $7^{\text {th }}$ week of post-partum. This agreed with results recorded previously by Yilmaz and Ucar [10].

\section{Conclusion}

Ultrasonography is a useful imaging modality for determining pregnancy, fetal development and its viability and detecting fetal resorption and fetal abnormalities which cause abortion or dystocia. Predicting the parturition date can help in managing parturition or planning a cesarean section in pregnant bitches with multiple mating or an unknown mating time. By sonography, postpartum uterine involution may be easily interpreted in the bitches, diagnose and manage reproductive disorders of the uterus.

\section{Conflict of interest}

All the authors have no conflict of interest to declare.

\section{References}

[1] Feldman, E.C.; Nelson, RW. (1996): Canine female reproduction, In:Canine and Feline Endocrinology and Reproduction, Ed; Pedersen D, WB Saunders, Philadelphia, USA, pp; 572591.

[2] Yeager, A. E.; Mohammed, H. O.; MeyersWallen, V.; Vannerson L. and Concannon, P. W. (1992): Ultrasono graphic appearance of the uterus, placenta, fetus, and fetal membranes throughout accurately timed pregnancy in beagles. Am. J. Vet. Res. 53:342-351.

[3]Johnston, S.D.; Kustritz, M.V.R. and Olson, P.N. (2001): Vaginal cytology in the bitch 
In: Canine and Feline Theriogenology, W.B. Saunders Company, Philadelphia.

[4]Bang, S. K. and Chang, H. S, (2007): Time of initial detection of fetal and extra-fetal structures by ultrasonographic examination in miniature schnauzer bitches. J. Vet. Sci, 8 (3), 289-393.

[5]Yeager, A. E. and Concannon, P. W. (1990): Association between the preovulatory LH surge and the early ultrasonographic detection of pregnancy and fetal heartbeats in beagle dogs. Theriogenology. 34: 655-665.

[6]Aissi, A, (2008): Aspects of ultrasonographic diagnostics of pregnancy in bitches depending on the first mating. Veterinary world, vol. 1 (10): 293-295.

[7]Aissi, A.; Alloui, N.; Slimani, C. and Touri, S. (2008): Preliminary study of the early ultrasonic diagnosis of pregnancy and fetal development in the dog. J. Anim. Vet. Adv., 7 (5): 607-611.

[8] Son, C. H., Kyung, A.; Kim, J. H.; Kim, S. H. and Cha-Soo lee (2001): Establishment of the prediction table of parturition day with ultrasonography in small pets dogs. Theriogenology. J. Vet. Med. Sci. 63 (7): 715-721.

[9]Anna, Domoslawska; Jurczak, A. and Janowski, T. (2011): A one foetus pregnancy monitored by ultrasonography and progesterone blood levels in a German shepherd bitch: A case report. Veterinarni medicina, 56 (1): 55-57.

[10]Yilmaz, O. and Ucar. M. (2012): Ultrasonography of postpartum uterine involution in a bitch. Kocatepe. Vet. J. 5(2): $55-58$.

$$
\begin{aligned}
& \text { الملخص العربي }
\end{aligned}
$$

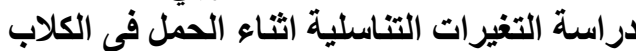

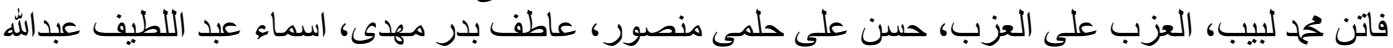

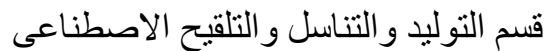

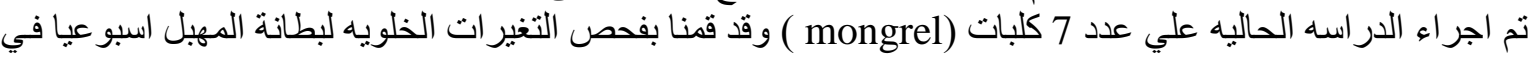

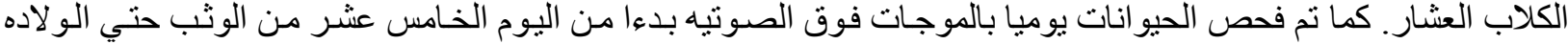

$$
\begin{aligned}
& \text { حتي يمكننا فحص ظهور التركيبات المختلفه أثناء الحمل لتحديد عمر الحمل. الكثف المبدئي عن المكونـات الحميليه وخـارج }
\end{aligned}
$$

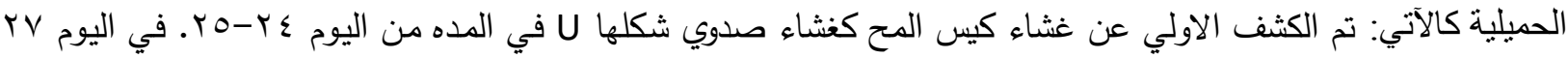

$$
\begin{aligned}
& \text { تم الكثف الاولي عن غشـاء حميلي ثالث صدوي (الغشاء السجقي allantois). في اليوم سזمن الحمل في الكلاب في } \\
& \text { السلالات المستعمله تم التعرف المبدئي علي السغد النطاقي (zonary placenta) كطبقه داخل جدار الرحم صدويه. وقد } \\
& \text { كان الظهور المبدئي للجنين في يوم ·r.وضع الجنين الاولي اما جنبا الي جنب لجدار الرحم أو يعتمد علي وجوده في تجويف } \\
& \text { السلي (chorion) في اليوم بr في السلاله الخليط. يتم كثف دقات قلب الجنين وظهورها كحركه مترجرجه صدويه وضاءه } \\
& \text { والتي تثبت حياة الجنين في اليوم rr. وكان شكل الجنين يتراوح من المستطيل وثنائي القطب الي شكل ذو قفبين ويتكون من } \\
& \text { حلتين علي شكل رقم (oblong to bipolar shape). ظهور مساحه غير صدويه في رأس الجنين وبراعم أطراف الجنين } \\
& \text { في اليوم 9r وكذا اكتشاف في حركة الحميل في اليوم بr في كل الكلاب المستعله في البحث. إمكان كثف الهيكل العظمي } \\
& \text { الخاص بالحميل في اليوم سٓ. }
\end{aligned}
$$

